\title{
Resilience and Hope: Exploring Immigrant and Refugee Youth Experiences through Community-based Arts Practice
}

\author{
Leah B. Lewis, Heather McLeod, Xuemei Li
}

\begin{abstract}
Aвstract Community-based arts practice is programming that informs and fosters essential components of well-being and belonging, including resilience, community attachment via interpersonal connection and exchange as preventive to mental health stressors. Our Art Hive is in a centre-city high school with immigrant and refugee youth in St. John's Newfoundland, where newcomers often face an insider/outsider dynamic of disconnection. The pop-up Art Hive is a publicly accessible and community-located art-making space grounded in Adlerian theory, collaborative community development, feminist thought, and social justice. Through a community-situated arts-based participatory process, we sought emergent themes. An earlier phase of our collaborative project involved visual art-making and exploring experiences of inclusion and belonging. A second phase of the project included some of the same youth and new members, adding local students invited by the immigrant and refugee youth. This phase explored resilience and hope as a feature of well-being and functioning and as having a relationship with immigrant and refugee youth experiences in smaller Canadian centres. The Art Hive, a form of community art therapy practice, is structured along seven social parameters: focus on intentional art-making, no critical commentary (positive or negative), non-evaluative in nature, no forced participation, witnessing, sharing, and participatory involvement of facilitators. The participant-planned and hosted final exhibit contributed to learning, sharing, and group cohesiveness. A focus group generated data on how the Art Hive informs cultural experiences and feelings of hope.
\end{abstract}

KeyWords Hope, resilience, refugee youth, community-based, Art Hive

\author{
"Hope" is the thing with feathers - \\ That perches in the soul - \\ And sings the tune without the words - \\ And never stops - at all - \\ And sweetest - in the Gale - is heard - \\ And sore must be the storm - \\ That could abash the little Bird \\ That kept so many warm -
}

Engaged Scholar Journal: Community-Engaged Research, Teaching, and Learning 


\section{I've heard it in the chillest land- \\ And on the strangest Sea- \\ Yet - never - in Extremity, \\ It asked a crumb - of me.}

\section{Emily Dickinson, “'Hope' is the Thing with Feathers" (public domain)}

We begin with this beautiful poem (Dickinson, 1951) because it captures our project's key theme. We explore the importance of hope and the impact it has on immigrant and refugee youth in their new life in Newfoundland and Labrador, in the capital city of St. John's, which is a small urban centre in the eastmost island in Canada known for its long winter and humid weather.

In the past decade, the province has seen a significant increase in the number of newcomers, among which many are of refugee background. This is an emerging situation as the province has been relatively homogeneous, with its population being predominantly white native-Englishspeakers, due to its European colonial history. Although over sixty Mi'kmaq, Inuit, Southern Inuit of NunatuKavut, the Northern Innu and Metis groups live in the province, they do not constitute most of the population (Grammond, 2014; Statistics Canada, 2016). Although we acknowledge our province's Indigenous cultural history, we are narrowing our subject area to newly arrived refugee and immigrant groups to Newfoundland and Labrador, focusing on arrivals between 2015 and 2019.

Even with the recent increase of newcomers, ethnic minority groups still constitute about two percent of the population, a notable increase from previous years (Statistics Canada, 2016). Most of the services and academic bridging programs have been set up for newcomers in the past decade and are located primarily in St. John's. A limited amount of school-based research has been conducted to investigate the challenges and needs of newcomer students, indicating that refugee students, in particular, suffered from educational gaps, subtle racism and micro-aggressive treatment, lack of social interaction with local students, and lack of tailored counselling service for refugee students' experiences, to name just a few (Baker, 2013; Baker, 2015; Li \& Grineva, 2016). Although small in number, community-based research projects point out issues such as language difficulties, employment challenges, social isolation, and so on (Anderson, 2012; Duggan et al., 2013; Li \& Que, 2015).

In this context, we designed the new approach of art-making to promote communitybuilding, enhance mental well-being, and express belonging. Our project began in 2016. In the first phase, we focused on community-building and a sense of belonging. In the second phase upon which this article is based, we explored how art-making helps newcomer youth in our research-site high school express their hopes and resilience in difficult times. Through our Art Hive work with newcomer youth, we drew from Adlerian Psychology and engaged with Bettner and Lew's Crucial C framework (1999). We explored how the singing bird of hope allowed spaces for these youth to grow and flourish on this strangest Sea and in this chillest land. 


\section{Our Context and Project}

In Newfoundland and Labrador, the diversity landscape has shifted in recent years with an increased influx of visible minorities from 1,865 newcomers in 2006 to 3,675 in 2016, resulting in a total representation of roughly $2.3 \%$ province-wide (Statistics Canada, 2016); a substantial increase from previous years, where between 2001 and 2005 newcomer arrivals totalled less than 1,000. This is on par with other Canadian cities, like Montreal, Toronto, and Vancouver.

In response to a recent provincial all-party report on the urgent need for mental health services in the province in Newfoundland and Labrador (Government of Newfoundland and Labrador, 2017), calls to action have been issued. These emphasize an increase and diversification of frontline mental health services necessary to address the urgent need for preventive, wellness shaping, and readily accessible community-situated service. This is because of frequent delays in accessing counselling support due to lengthy waitlists within our public health system. Similar to other regions in Canada, private practitioners are sought as a means of quicker access. However, private practice's nature means that these services are more readily accessible to individuals able to pay the $\$ 75.00-\$ 180.00$ CAN local hourly rate or who have access to insurance programs that cover some or all of this fee. The inherent implication is access to privatized service that is facilitated by considerations like income. But how do individuals with low- or no-income access community support, including counselling and counselling-like services? Other population considerations include the broader array of barriers experienced by disenfranchised and homeless youth, youth with precarious living situations, and new immigrants. Navigating social and health systems is often complicated and alienating. Such social barriers inform higher levels of absenteeism public health services, especially counselling and psychological services for newcomer youth 16-20 years of age (Anisef \& Kilbride, n.d.). Somewhat isolated, at times vulnerable, communities like these require considerations for facilitated access. These considerations include the location of counselling services, nature of the space, language supports and multiple approaches that support communication preferences, awareness of stigma sensitivities and nuances of relationship building being subject to a cultural context, including experiences of power in institutional settings (Chaturvedi, 2016; Tillson, 1997). As well, cultural and identity differences form other barriers to accessing services.

We distinguish services that are preventive from services that are acute interventional. Acute interventional mental health services are often sought at institutional health servicing levels. Differently yet importantly, preventive services support the maintenance of wellness by setting a foundation of supportive programming that strives to meet social engagement needs through the facilitation of interpersonal functioning and exchange and highlight experiences of empowerment, connection, and competency-building that inform overall functioning and wellness. Preventive programming can be understood as programming that contributes to the building of a functional foundation from which increased coping tolerance and resilience can be drawn, thereby decreasing the likelihood for required acute care. These are often communitysituated, accessible services within local settings such as schools, community centres, and churches, and are multi-faceted in content.

Throughout our project, we focused on the role that community arts programming plays 
as wellness-fostering via creative process, that is art-making in an interpersonal context. As a form of practice that reflects the ideals of community psychology, social justice, and feminist thinking, we present the added consideration of historically subjective concepts of resilience and hope as indicators of overall wellness. Through our Art Hive work with newcomer youth, we engage with Bettner and Lew’s Crucial C framework (1999), drawn from Adlerian Psychology. We discuss the relationship between interpersonal wellness being founded on our ability to engage with others to perceive and experience our value (Bettner \& Lew, 1999), namely by connecting, being capable, counting, sharing courage, and the developing prevalence of resilience and access to hopeful thinking in our participants.

Studies that investigate newcomers' experiences of transitioning to our province have highlighted the prevalence of newcomers' disconnect and their feelings of being outsiders (Anderson, 2012). Instances of racism have also been experienced, possibly informing newcomer tendencies to move to larger urban centres like Toronto and Montreal where cultural pockets are more readily established and accessible (Baker, 2013; Baker, 2015; Duggan et al., 2013; Reitz, 2005). From an economic lens, the province of Newfoundland and Labrador values in-migration as positive for both population growth and diversifying the provincial economy. Consequently, research linking the economic benefits of immigration in our province recognizes that developing community engagement and attachment for newcomers to our province further increases the likelihood that new Canadians will stay and make a life here (Duggan et al., 2013). Such studies call for an expanding of community-situated scholarship that seeks to deepen our understanding of the lived experiences of newcomer families in Newfoundland and Labrador.

\section{Methodology}

Our project brought together participatory community-based research, using an arts-based framework and applying a pop-up Art Hive program for weekly sessions in collaboration with a local English as a Second Language (ESL) high school program. We ran two consecutive Hive programs; the first with solely newcomer youth, the second expanded invitations to local youth based on newcomer requests to include others.

We draw from Hesse-Biber (2005) and Leavy $(2005,2017)$ in our design; namely privileging location, collaborative decision-making in the grand portion of our process, (including program modifications that suited the students' desires for enhanced social engagement with other youth outside of newcomer programming); as well as student driven and led designing, curating, and preparing our Art Hive open house for other school members and the public attendance. Students opted to expand our second series of sessions when they proposed inviting Canadian peers to participate in the Art Hive sessions. The emerging creative process was also considered in that students most often opted to create and work on personal projects. However, to some degree, students' projects were introduced by the Hive facilitator. Data was collected via interviews with student and teacher participants, focus groups, and documented art work that explored experiences of the Art Hive sessions as these related to experiences of belonging and inclusion; with a subsequent focus group adding the feature of hope and its 
relationship to belonging and inclusion. The creative process and focus are informed at both individual and group levels. They are iterative and segue from creative focus to creative focus, i.e. sketching may evolve into painting and lantern-making into sculpting, depending on an individuals' exploration and creative process. Our research combined the central tenets of ArtsBased Research (ABR) and Community-Based Participatory Research (CBPR), namely the collective and intentional use of creative methods and process as a means of expanding our understanding of human experiences. Arts-Based scholarship uses metaphor, symbolism, and other aesthetic features to explore, create, and expand our meaningful understanding of the human condition. ABR scholarship considers both processes and output (product) as relevant to how knowledge is creatively developed (Baden \& Wimpenny, 2014). ABR is grounded in post-structuralist thought. Hence, it acknowledges that art-making and engagement with the arts as meaning-making acts are subjectively informed by context and circumstance.

Members were recruited through assistance from gatekeeping school staff, namely English as a Second Language (ESL) teachers and the school counsellor. A pizza event and presentation were held on-site during a lunch break, during which materials about Art Hives were distributed and consent forms were provided to interested students under the age of 18 . The first series of Hive sessions ran for 16 weeks throughout the winter of 2017, with the second series of eight sessions following in the fall of 2017.

Our core arts-based framework utilized the art therapy concept of Art Hive. Art Hives, which are a community-situated framework, are open-access art studios for social engagement through art-making. Art Hives act as "third spaces" for learning bringing together theory and practice in an applied setting (Timm-Bottos \& Reilley, 2014). Students who engage in service-learning in such centres gain knowledge from multiple levels, including community psychology and practice theory, with enhancements in person-centred perspective through lived experiences of engagement, increased empathy, interpersonal connection and emotional maturity via increased critical thinking. Students gain more complex visceral understandings of disenfranchisement and the power and access experiences relating to public mental health service. Through third space community learning, universities foster a community presence that expands understandings of knowledge by engaging with themes of classism that inform access to service, using collective engagement as a means to building knowledgeable and proactive solutions.

Art Hives are non-clinical in their approach and are structured along seven social engagement parameters: focus on intentional art-making, no critical commentary (positive or negative), non-evaluative in nature, no forced participation, witnessing, sharing, and participatory involvement of facilitators. The participant-planned and hosted final exhibit contributed to learning, sharing, and group cohesiveness. Two focus groups were used to generate data on how our Art Hive informed cultural experiences and feelings of hope.

Art-making encourages the exploration of lived experience in conjunction with learning about social issues. Because the arts easily apply in outreach programming, they fit well as tools for working with people in non-intimidating ways, privileging human experience in imagecreation and the space that houses it. Collaborative spaces provide a broad playing ground for 
developing self-directed skill and competency, channelling ambiguity and confusion towards improved clarity and a coherent experience of inclusion and belonging. These collective experiences foster increased psychological functioning via experiences of superiority (Adler, 1935), where increased self-awareness and functioning occurs in response to interpersonal contexts. This allows for reciprocal exchange, which builds confidence, competency, connection, self-value, and interpersonal courage (Eleniak et al., 2016). Timm-Bottos (2016) presents community-situated Art Hives as locales of healing; third spaces fostered by and within communities possessing liminality that is not home or institution. Traditional art therapy and all counselling and psychology practice can limit our ways of knowing due to institutional medical-model lenses of practice.

In contrast, Timm-Bottos (2016) calls for spaces that engage with the surrounding community. These spaces are where service-learning students may engage in applied learning opportunities that are both experienced and embodied, and which privilege clients' ability to motivate their healing via client-driven practice (Burt, 2011; Timm-Bottos, 2016). Our project included two graduate assistants who co-facilitated Hive sessions and data collection and observed the emergence of social engagement via the Crucial Cs.

Kottman (1999) has discussed the essential need for the establishment of the Crucial Cs (Bettner \& Lew, 1999) in childhood as central to interpersonal functioning and self-value and contribution and engagement via experiences of connecting, capability, counting, and courage. Connecting highlights engagement with others and friendship development. Through connecting with others, children begin to develop a sense of belonging in a group. The alternative - disconnection, the inability to connect — brings about feelings of isolation and social insecurity. Lack of connection in early development is likelier to inform negative, rejecting social responses. Capability, also understood as competency highlights one's recognition of contribution through skill.

Additionally, being capable speaks to self-care and the ability to achieve, self-motivate, and take on responsibility for oneself. Lack of a sense of capability can manifest in dependency, control-driven anxiety, and general feelings of inadequacy. Experiences of being significant, noticed, being part of a group or community is referred to as counting. Counting is the perception and belief that one contributes and makes a difference in their surroundings and is valued for their presence and contribution. Individuals who experience counting recognize their absence will be noticed. Experiences of being valued are more substantial in some settings and less so in others, but a general understanding of value is present that allows for valuing others as well. Individuals who do not learn the experience of being valuable often experience feelings of insignificance, of feeling not noticed and not mattering. This is associated with an increased likelihood of poor self-concept and self-esteem, sometimes manifesting in an overemphasizing of self via acting-out behaviours. Courage relies on the three preceding $\mathrm{Cs}$ in that if one possesses a degree of self-perceived connection with others, capability, and counting or being valued within their surroundings, they are likelier to experience courage. Courage, as Kottman (1999) describes it, manifests through displays of resiliency. This is the belief that taking a chance can result in an increased sense of self, hopeful and optimistic thinking, 
and accomplishment. Having courage makes one likelier to try new things and to experience curiosity and social comfort. Lack of courage results in social hesitancy, an inability or difficulty in trying new things, and a tendency to give up or experience high levels of despair when plans don't work out. Without courage, one can be intimidated by new experiences.

\section{Situating Arts-Based-Research in Communities}

Community-located arts-based scholarship operates in a complementary fashion due to Art Hives being community-situated. Community-based Participatory (CBP) approaches are referred to via multiple terms, including Participatory Action Research (PAR) and Participatory Research (PR), both often applied somewhat interchangeably. Participatory approaches to research actively and intentionally engage with participants in some or all parts of a study in the shaping of what and how information is sought, and social challenges approached (Leavy, 2017). In our case, we were interested in exploring themes of belonging and inclusion together with our participants as it relates to the lived experiences of newcomer youth in our region.

Privileging collaborative approaches with non-academic groups, CBP approaches are often project-based in community locations and strive to address an existing challenge or problem (Leavy, 2017). Because such work can involve an experimental approach to navigation,

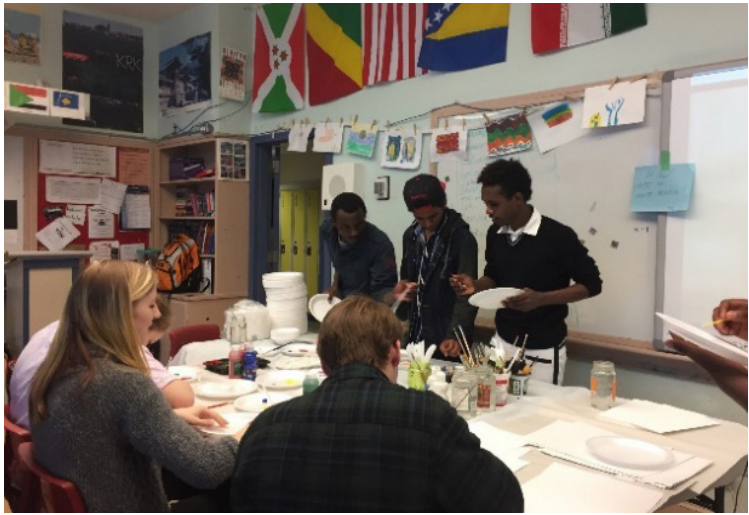

Figure 1. Students instruct printmaking using Styrofoam plates CBP research calls for necessary flexibility along the way, allowing for modification if required. Such flexibility fosters the inherently cooperative nature of participatory design and input and strengthens rigour and continuity due to its multi-perspective positioning. In our case, we took an arts-informed approach to our design by privileging art-making as the core activity. Most importantly, collaborating with a non-native-English-speaking newcomer population

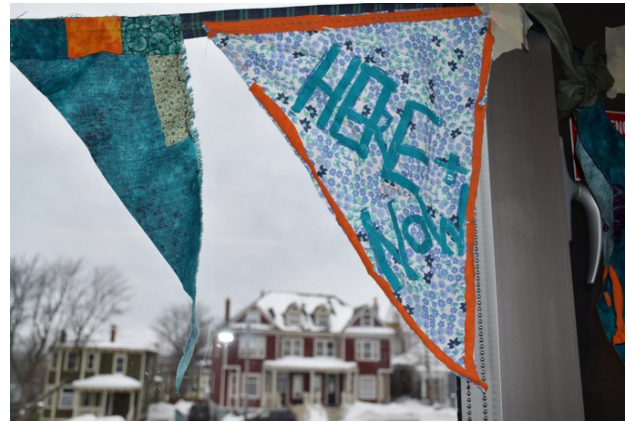

Figure 2. Cloth flags hang in the classroom demanded consideration of alternate methods to conventional language-driven investigation. Our design aligned nicely with the embedded subjectivity in art-making and hence facilitated participants' engagement.

To explore newcomer youths' feelings of inclusion and belonging, we hosted a series of Art Hive sessions over two school years in a local high school in St. John's. Using a participatory community-located art-based approach, we partnered with English as a Second Language 
(ESL) programming and invited newcomer youth to participate in the program. In the first-year, sessions were offered weekly for sixteen weeks and included any student from the school's newcomer programming. Attendance increased over time, culminating in an open house art exhibit curated and hung by the students themselves. The open house welcomed student peers from within the school, as well as members of the public. The youth hosted all facets of the open house, including providing tours and miniprintmaking workshops for attendees.

The second series of eight weekly Art Hive sessions were conducted in the fall of 2017, revisiting our original framework and consulting with the youth about desired modifications. The participants suggested expanding the Hive sessions

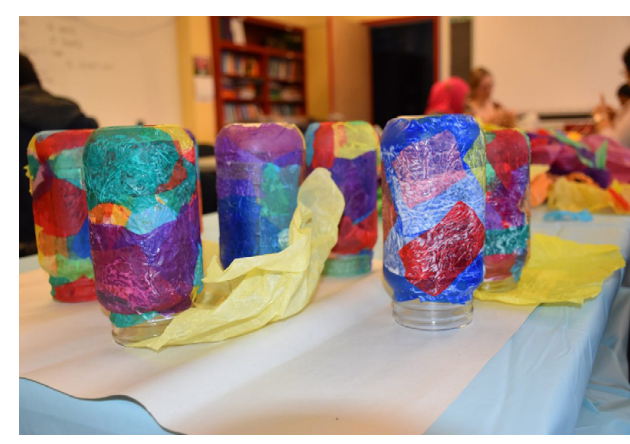

Figure 3. Glass lanterns made by students to invite local friends from within the school who had not been included in the first Hive program. We consequently grew the Art Hive and included Canadian participants. The climate and nature of art-making and engagement shifted with Canadian students' addition; students became more socially engaged with a diverse peer group, experimented with English more noticeably, and connected with facilitators increasingly with each Hive session. A second focus group was conducted at the end of the eighth session to determine how the Art Hive was experienced considering these alterations. This focus group added the youths' perspective on the concept of hope related to their newcomer experiences and the Art Hive. We focused on hope in part due to our first stage of data collection, which indicated that the Art Hive itself was a non-evaluative location for social engagement and a site for connecting with new friends (Lewis et al., 2018). Additionally, the youths' interpersonal engagement increased through the surfacing of all four of Bettner and Lew's Crucial C framework (1999). We wanted to explore how hope informs experiences of inclusion, belonging, and the experience of being part of a community.

Community Art Hive programming is primarily inspired by merging Art Therapy practice and social justice disciplines and community psychology frameworks. Hives offer a versatile and widely accessible opportunity to engage in process-focused art-making as a means of enhancing wellness and increasing interpersonal functioning via grassroots community locales. Due to its ability to engage via non-verbal, creative (aesthetic) process, arts-based scholarship suits community settings and is accessible to diverse groups (Burt, 2011; Malchiodi, 2012; Moon, 2009). Additionally, arts-based approaches in community settings, using the participatory methods discussed above, narrow the gap between theory and practice and allow for actionoriented knowledge discovery collectively-driven by stakeholder positioning and input. Argyle and Bolton (2005) promote the use of community arts programming as beneficial to mental health and functioning due to inherently supportive components of social engagement and exchange in shared creative spaces. Moon (2009) argues that incorporating art-making as a non-verbal creative process is a worthwhile consideration for mental health programming 
due to the inherent social interactions (both inter and intrapersonal) that occur when artmaking is the core focus of service application. These social interactions include increased communication and identity development and tools for reflection and social interaction that are contained and self-directed. Other facets of art-making in a social setting include less reliance on verbal communication, with creative images developed as a means of sharing one's presence and identity visually.

Community psychology frameworks highlight collaborative, community-situated, shared spaces as promoting connecting, thereby fostering experiences of empowerment. Community arts initiatives privilege the concept of well-being, rather than health, because well-being connotes a state of self-acceptance that includes a holistic sense of self and what it means to be well; i.e., illness and well-being can coexist, whereas health and ill health cannot. Thus, when we engage individuals from a holistic lens, we can privilege wellness regardless of health status. Engaging with others within community-located creative locales acts as a form of frontline preventive care for diverse and marginalized populations who typically do not, or cannot, access public institutional care or don't require structured care but who seek community support towards increased wellness through engagement. Community located services promote positive psychology in an applied community context; current evidence supports community engagement and connected programming to inform improved mental health functioning in concrete ways (Argyle \& Bolton, 2005). Argyle and Bolton's (2005) look at group art sessions in community contexts, names such contexts as possessing a secondary therapeutic effect due to increased self-perception and agency that participants experience in response to communitybased creative groups that highlight interpersonal contexts as spaces that foster interpersonal connection, which in turn fosters higher levels of community attachment.

\section{Hope and Resilience in Community Practice}

Community psychology research has helped us further understand the relevance of wellness, such as resilience, hope, and experiences of belonging to a community or group as central wellness features. While deemed to be subjective concepts, we understand that resilience develops within engaged contexts, especially as it relates to experiences of struggle and trauma. When resilience is present, the ability to cope and move through difficulty strengthens (Wolf, 2014). Community engagement and experiences of belonging and attachment to a community group creates context through which such dynamics might be fostered. Community psychology privileges locating practice in community settings that build programming collaboratively, and according to population context and need. It is population focused and acknowledges inequality, racism, sexism, and economic factors (Wolf, 2014). Community psychology focuses on collaborative system change via enhanced empowerment experiences drawn from within the community group itself. Practitioners look to the community for its inner resources as a means of building resilience and action. Cadell et al., (2001) highlight the importance of community connection and attachment to foster strong and inclusive community groups. Connected communities make for a greater likelihood of enacted empowerment, support, advocacy, exchange, and altruism between members. Community building, empowerment, 
and resilience contribute to a cyclical wellness model, whereby the three work together towards comprehensive community-sourced wellness, described as a 'critical element of hope' (Cadell et al., 2001; Catlett, 2017).

Hope plays a critical role in fostering foresight and optimistic anticipation of positive change. Hope indicates planning for the desired outcome, understanding that current states of life are temporary - allowing for concentrated focus on the moving through, coping with, and termination of a difficult event towards an improved state. Hope allows for planned accomplishing, planned relationship, the understanding that challenges are temporary. We name hope as a central feature of resiliency. Resilience involves tools for coping, preparation for effectively and efficiently traversing difficult experience, bouncing back to a state of conscious connection and wellness. Adverse experiences during childhood can be a challenge to resilience development; nevertheless, resilience can be learned and fostered. The culturally responsive practice involves working with the individual's context and attending to dual language learners, cultural transitions and lack of family supports (Catlett, 2017; Croucher, 2009; Pearce, 2008). We acknowledge the subjectivity of wellness, that wellness has surfaced within academe in health and medical literature, as well as via critical models that recognize that wellness is a broad concept that considers the important factors of context, privilege and power, disenfranchisement, and access to service (Wolf, 2010, 2014). Regardless, we know that many maintain resilience, even in the face of struggle. Inner strengths that become accessible during difficult transitions are informed by community wellness and functioning. Resilience is defined as the ability to "adapt to, cope with, and even be strengthened by adverse circumstances" (Sannapieco \& Jackson, 1996). This involves the ability to negotiate difficult experiences, even in expanded or enhanced ways. Resilience is informed by family, temperament, and the strength of attachments to family, friends, groups, and the collaborative resources formed (Wolf, 2010). Our interest in the role that resilience plays helps us understand how supports can be provided for struggling groups. We know that resilience isn't present for all, but that it can be fostered via experiences enacted through collaborating connected communities (Wolf, 2010, 2014).

Gundy et al., (2011) share their community attachment or detachment model with us in relation to problem issues: depressed mood, substance use, delinquency, and personal attributes. Community attachment, which can be understood as relational cohesion is related to reducing these and the overall stress process. When psychosocial resources are more prevalent and accessible, the nature of these resources contributes the community attachment. From group counselling theory, we understand that connected cohesive groups invite intimacy via an interpersonal exchange, increased trust, disclosure via exchange, instillation of hope, and a desire to do good with and for others with increased altruism (Yalom, 2005). Shared community experiences (negative or positive), like socioeconomic status, and sharing experiences of helplessness can inform universality and cohesion experiences. These are useful resources to enhance experiences of attachment, security, and empowerment (Gundy et al., 2011; Yalom, 2005). In contrast, when experiences are kept in isolation, they are likely to be felt in a vacuum, increasing self-deprecating self-perceptions and feelings of despair.

Community cohesion is a psychosocial resource and a goal of community psychology 
practice. A feature of lesser stress experiences includes an interpersonal sense of self. Community attachment is a central feature of shaping youths' social well-being. Identities are explored, and the shaping includes acceptance, group belonging, social inclusion and social resources where help and support can be accessed safely. Some cautions include extreme attachment and over entrenchment to the degree that it can mitigate opportunities to explore outside the community group. Community detachment is associated with a lack of experiences of belonging and inclusion, exclusion experiences, a higher likelihood of identity-protecting behaviours (e.g., bullying), and conformity demands. In this situation, autonomous identities are unsafe, and isolating behaviours can be challenging in some groups (rural living).

The community attachment model used by Gundy et al. (2011) is relevant to newcomers, whose experiences include the rebuilding of community and an increased need for community attachment. Pearce (2008) discusses the role of social capital for newcomers seeking integration and inclusion and the importance of neighbourly trust as a feature of the experience of integration and belonging - that particularized trust in one's community can enhance experiences of belonging and inclusion. Professionals working with newcomer communities should consider the centrality that hope, resilience, efficacy, and optimism in those we work with (Catlett, 2017) contribute to community integration and overall wellness.

We (Lewis et al, 2018) draw connections with these tenets of community psychology and arts practice, as falling neatly in agreement with the Crucial Cs framework (Bettner \& Lew, 1999). These frameworks provide tools for fostering community engagement and attachment, collaboratively moving towards defined senses of efficacy, and empowerment experiences through resilience and hope. We also consider the nuances embedded within arts-based methods that inform knowledge exploration by combining aesthetic and cognitive-emotional responses. We value the lack of reliance on a linguistic exchange, supported instead by the value that aesthetic engagement brings to art-based engagement (Leavy, 2009; Machida, 2006; Mcniff, 1998). The field of Art Therapy supports the core notion that Arts-based approaches can work together with psychological theories, such as Adlerian-informed frameworks. This is due to the emotional and cognitive stimuli that are brought about when engaging creatively projected images (Moon, 2009).

\section{Findings and Discussion}

Many of these themes were brought home during our final focus group that sought thoughts on the experience of resiliency and hope and its significance in the context of being a youthful Art Hive participant and newcomer to Newfoundland and Labrador. The participants shared that hope for them was an indication of improvement. Hope surfaced via three apparent perspectives. One was at a micro level, demonstrated through a hopeful desire to make more art, to produce art following our facilitator's programming, and to produce self-made, selfconceived art that is new and different. Another perspective of hope seemed to surface from more of a macro level of thinking. One participant described hope as a form of waiting: "Hope; I'm waiting for something, something to change...[for the better]. With hope, you feel it will be better...make an announcement to...school, [so that we can...] mix together." On the 
development of future hives, students indicated a hope that programming would expand.

This stemmed from a discussion of the experience of inviting Canadian students within the school to take part in the second Hive program. A participant said, "[having Canadian students here] ... yes, I know more people now!" Reflective observations from the researchers and teachers provide us with additional insight into how belonging, inclusion, resiliency, and hope were fostered for student participants through the Art Hive sessions. Student anxiety was decreased due to the non-evaluative nature of the sessions, teacher/student connections increased through the parallel process and collaborative art-making due to teacher engagement, student participants instructed teachers on art techniques, and cultural exchange and sharing of stories occurred through art images and flag images painted by select students.

Teachers noted the bringing together of multiple cultures in a single art group, naming the connections during Art Hive as noticeably more potent due to the sessions. They also observed students coming together outside of Art Hive time, having not socially spent time together before this experience. The Art Hive was named a unique activity experienced by newcomer students, different from other activities like sports and single session field trips, primarily due to the repeated opportunity to form connections both between students and between teachers and ESL students. A teacher noted:

Sharing an experience together, making connections...just connected...it gave them something special, ... allowed them to feel special, feel safe...Some have issues with literacy...I feel that my connection is stronger with some of the students, just because we were [making art] side by side.

The development of confidence and engagement was observed through the public open house art exhibit being hosted from the students' familiar space: their classroom. Their willingness and ability to engage with new people was evident through their leadership drive. Of the final open house exhibit, our teacher participant shared, "They all seem so willing to want to give, to connect... it was perfect to end that way... it was a great idea to do it in their space...". The teacher later added, "I really saw them taking a leadership role... They owned it. The leadership...they don't get a lot of opportunity for that.... They were ready to take that on." The teacher input provided us with a heightened understanding of the evolving leadership of the ESL students, allowing students to experience increased ownership of the Hive process.

Finally, our teacher participants' reflections highlighted the importance of community connecting as an effective way to foster tolerance in diverse groups. One teacher shared that “...bringing people together is really important... with the world, and politics and what's going on...from all different backgrounds...you just learn to respect each other, as humans. It's [the Art Hive] a great way to come together." The teacher participants engaged more comprehensively in the Art Hive sessions as they progressed over the school year. This feedback about observed cohesion, tolerance, and agency surfaced over time and observed participation. We feel that the teachers' act of participation informed this perspective.

Jani and colleagues (2015) provide us with some reference for the prevalence of hope as 
a feature of resilience in newcomer youth. They note the presence of hope is often a feature of resiliency among children and youth who come from experiences of trauma in their home countries, at times including family separation. Such cases often result in families separated during the migration process. Supports for integration are deemed essential, where health and productivity outcomes rely on a sense of established inclusion and belonging.

The field of community psychology highlights the importance of interpersonal supports as central to well-being. We are in an era where perspectives on mental health and inclusion consider the role that space, community, and creativity play in fostering human connection and belonging - community-located arts-based participatory approaches to knowledge discovery work from creative engagement. Engagement is highlighted as a necessary feature of scholarship that invites participatory input and is further facilitated by the act of making (process) and observing or witnessing art (product resonance) (Moon, 2009). The embedded feature of art-making in a group atmosphere seemed to encourage engagement,

Concepts like resilience, hope, and belonging are subjective to context. They are difficult to measure, except that we know their presence heavily informs our ability to adapt, cope with difficult or stressful experiences, and reconnect. Kottman (1999) connects interpersonal engagement and courage to a resilient outlook, including hope and optimistic temperament as well-being and functioning. Hence, we offer the role that hope plays within the desire to connect with others and form social bonds. The desire to achieve a sense of belonging and intimacy with others motivates our willingness to explore new social contexts. Even small moments of connection inform whether individuals return towards a fostering of deeper, more profound connections.

We also ponder the role of enhanced connection in a shared creative space. The forming and fostering of shared public space that invites creative exchange that is not language dependent is presented here as a consideration for community arts practice that highlights interpersonal connection to value inclusion and newcomers' integration. Our community pop-up Art Hive program provided a space for youth to engage creatively in a non-evaluative space. Art-making as a practice is both an independent and social act that invites participants to work together comfortably, without judgement of aesthetic or artistic skill.

While Art Hives strive to minimize power differentials, this piece is not always fully achieved. Hosting a pop-up program in a school brings some implied hierarchies that are difficult to avoid, i.e., teacher/student environments are inherently hierarchical. We were aware of such dynamics and sought to minimize hierarchies by hiring a community Art Hive facilitator and student RAs close in age to the pupils. Some relationships shifted in response to the Art Hive environment; the classroom teacher noted a shifting of relationship with her students, experiencing more intimate exchanges over parallel art-making practice during Hive sessions when compared to her usual teacher-student exchanges. This resulted from her role being one of the Art Hive participants, rather than an evaluator. As our program progressed, the relationships between researchers and students heightened, in part, due to much shared decision-making about the process. The final exhibit planning and curating and the studentfacilitated final workshops were hosted independently by the students and required no support 
from research or coordinating staff. That said, we acknowledge that power structures are complex and are informed by place, context, and many additional cultural nuances, not the least of which are gender and religious belief systems.

The immigrant and refugee youth opted to include local youth by invitation for the final eight-week Art Hive. The result of newcomer participants voicing a desire to diversify our group by asking selected Canadian peer friends to participate in our weekly Art Hive was that our group's climate shifted with a handful of new additions and resulted in a more established social engagement.

This paper has explored how creative engagement can assist with experiences of belonging and inclusion for newcomer youth in our province. We also note the relevance of hope to the newcomer experience and that the future for our youthful participants is at least partially infused with hope. We also acknowledge the role of creative engagement in community connecting and wellness. Hence, our current and upcoming projects include engaging the immigrant and refugee youth participants interested in digital storytelling supported by a community engagement grant from Memorial University. As well, and mainly in response to our findings during our work on The Open Studio Project, our team is currently developing a permanent community-embedded Art Hive, The Hearthstone Community Art Hive. This location prioritizes further enhanced creative engagement and collaborative scholarship, including opportunities for open studio drop-in sessions with mixed-identity groups.

\section{Acknowledgements}

The appropriate institutional research ethics boards approved this research. It was supported by a sub-grant from the Social Sciences and Humanities Research Council's (SSHRC) Pathways to Prosperity (P2P) Partnership Grant, and a Research and Development Grant from Memorial University's Faculty of Education.

\section{About the Authors}

Leah Lewis (corresponding author) is a registered creative arts therapist and psychotherapist with a background in counselling psychology. Her research interests are arts-based and communitysituated. Her current projects include the Open Studio Project, an Art Hive with newcomer youth, and Digital Stories with Newcomer Youth. Her other interests include arts-based health inquiry. Email: leah.lewis@mun.ca 
Xuemei Li is an associate professor at the Faculty of Education, Memorial University of Newfoundland. Her research interests include newcomer (immigrant, refugee, \& international student) integration in Canada, particularly in Newfoundland, methodology in teaching English-as-a-second-language, English academic writing, and cross-cultural identity reconstruction. She publishes, teaches, and supervises in these areas.

Heather McLeod is a Professor (arts education) in the Faculty of Education, Memorial University of Newfoundland. She has served as Editor-in-Chief of the Canadian Review of Art Education, and has been recognized for excellence in curriculum development (national award) and teaching (faculty award). She taught in BC and Nunavut and worked in communications for a teachers' union and government.

\section{References}

Alder, A. (1932). What Life Should Mean to You. Allen \& Unwin.

Anderson, W. J. (2012). Immigration in Rural Newfoundland: Individual and Community Change. Unpublished doctoral dissertation. University of New Mexico. Retrieved from https:// digitalrepository.unm.edu/cj_etds/30/

Argyle, E., \& Bolton, G. (2005). Art in the community for potentially vulnerable mental health groups. Health Education, 105(5), 340-354. https://doi.org/10.1108/09654280510617178

Association for New Canadians (2013). Annual report. St. John's, NL: Retrieved from http://www. ancnl.ca/userfiles/files/ANC-AnnualReport2013\%20REVISED.pdf

Baden, M.S., \& Wimpenny, K. (2014). A Practical Guide to Arts-Related Research. Sense Publishers.

Baker, J. (2013). Just kids? Peer racism in a predominantly white city. Refuge: Canada's Journal on Refugees, 29(1), 75-85. https://doi.org/10.25071/1920-7336.37508

Baker, J., Price, J., \& Walsh, K. (2015). Unwelcoming communities: Youth observations of racism in St. John's. Journal of Youth Studies, 19(1), 103-116. https://doi.org/10.1080/13676261.2015 .1052048

Bettner, B. L., \& Lew, A. (1990) Raising Kids Who Can. Connexions Press.

Block, D., Harris, T., \& Laing, S. (2005). OS process as a model of social action: A program for atrisk youth. Art Therapy, 22(1), 32-38. https://doi.org/10.1080/07421656.2005.10129459

Cadell, S., Karabanow, J., \& Sanchez, M. (2001). Community, empowerment, and resilience: Paths to wellness. Canadian Journal of Community Mental Health, 20(1), 21. DOI:10.7870/ cjcmh-2001-0002

Catlett, C. (2017). From article to action: Building hope, efficacy, resilience, and optimism. Young, Exceptional Children, 20(4), 191-193. https://doi.org/10.1177/1096250617741018

Chaturvedi, S. (2016). Accessing psychological therapies: Homeless young people's views on barriers and facilitators. Counselling and Psychotherapy Research, 16(1), 54-63. https://doi. org/10.1002/capr. 12058 
Conrad, D., Smyth, P., \& Kendal, W. (2015). Uncensored: Participatory arts-based research with youth. In D. Conrad, \& A. Sinner (Eds.), Creating Together: Participatory, Community-based, and Collaborative Arts Practices and Scholarship across Canada (pp. 21-39). Wilfrid Laurier University.

Croucher, S. M. (2009). How limiting linguistic freedoms influences the cultural adaptation process: An analysis of the French Muslim population. Communication Quarterly, 57(3), 302-318. https://doi.org/10.1080/01463370903109929

Curlette, W. L., \& Granvill, H. G. (2014). The four crucial Cs in critical friend groups. The Journal of Individual Psychology, 70(1), 22-30. DOI: 10.1353/jip.2014.0007

Duggan, P., Fang, T., \& Gunderson, M. (2013). Macroeconomic impacts of Canadian immigration: Results from a macro model. British Journal of Industrial Relations, 51(1), 174-195. https:// doi.org/10.1111/j.1467-8543.2012.00905.x

Elena, D., Canning, S., Demill, K., \& Samra, R. (2015). Open art therapy studios on campus: A case study, Adler university, Vancouver, $B C$. Unpublished manuscript. Retrieved from http://www. mentoringstore.ca/open_art_therapy_studios_on_campus_a_case_study.pdf

Hesse-Biber, S. N., \& Leavy, P. (2011). The Practice of Qualitative Research (2nd ed.). Sage Publications.

Jani, J., Underwood, D., \& Ranweiler, J. (2016). Hope as a crucial factor in integration among unaccompanied immigrant youth in the USA: A pilot project. Journal of International Migration \& Integration, 17, 1195-1209. https://doi.org/10.1007/s12134-015-0457-6

Julian, D. A. (2006). A community practice model for community psychologists and some examples of the application of community practice skills from the partnerships for success initiative in Ohio. American Journal of Community Psychology, 37(1-2), 77-93. https://doi.org/10.1007/ s10464-005-9004-5

Kalmanowitz, D. (2016). Inhabited studio: Art therapy and mindfulness, resilience, adversity and refugees. International Journal of Art Therapy, 21(2), 75-84. https://doi.org/10.1080/1745483 2.2016.1170053

Kottman, T. (1999). Integrating the crucial Cs into Adlerian play therapy. Individual Psychology, 55(3), 288.

Leavy, P. (2009). Method meets Art: Arts-based Research Practice (1st ed.). Guilford Press.

Leavy, P. (2017). Handbook of Arts-based Research. Guilford Publications.

Lepawsky, J., Phan, C., \& Greenwood, R. (2010). Metropolis on the margins: Talent attraction and retention in St. john's city-region. Canadian Geographer, 54(3), 324-346. https://doi. org/10.1111/j.1541-0064.2010.00315.x

Lewis, L., McLeod, H., \& Li, X. (2018). The open studio: Exploring immigrant and refugee students' experiences of belonging. Cultural and Pedagogical Inquiry, 10(1), 5-21. https://doi. org/ $10.18733 /$ cpi29363

Malchiodi, C. (2012). Art therapy in practice: Ethics, evidence, and cultural sensitivity. In C. Malchiodi (Ed.), Handbook of Art Therapy (pp. 42-51). Guilford Press.

McNiff, S. (1998). Arts-based Research. Jessica Kingsley.

McNiff, S. (2018). Philosophical and practical foundations of artistic inquiry: Creating paradigms, methods, and presentations based in art. In P. Leavy (Ed.)( $1^{\text {st }}$ ed.), The Handbook of Artsbased Research (pp. 22-37). Guilford Press. 
Moon, C. H. (2009). Studio Art Therapy: Cultivating the Artist Identity in the Art Therapist. Jessica Kingsley.

Office of Immigration and Multiculturalism, Province of Newfoundland and Labrador (2014). Immigration: Why it Matters. https://www.gov.nl.ca/immigration/files/Benefits-ofImmigration-for-Newfoundland-and-Labrador.pdf

Pearce, W. J. (2008). Bridging, bonding, and trusting: The influence of social capital and trust on immigrants' sense of belonging to Canada. Working Paper Series. http://community.smu.ca/ atlantic/documents/2009.01.06WP18Pearce.pdf

Reitz, J. G. (2005). Tapping immigrants' skills: New directions for Canadian immigration policy in the knowledge economy. IRPP Choices, 11(1), 1-18.

Statistics Canada. (2006). Visible minority population by census metropolitan areas: 2006 census - St. John's, Halifax, Saint John, Saguenay. http://www.statcan.gc.ca/tables-tableaux/sum-som/101/ cst01/demo53a-eng.htm

Stein, C., \& Faigin, D. (2015). Community based arts initiatives: Exploring the science of the arts. American Journal of Community Psychology, 55, 70-73. https://doi.org/10.1007/x104649698-3

Tillson, T. (1997). New coalition lobbies for multi-language counselling [Ethnocultural Coalition: Access to Addiction Services]. The Journal - Addiction Research Foundation, 26(6), 1. https://www.proquest.com/magazines/new-coalition-lobbies-multi-language-counselling/ docview/223321864/se-2?accountid=14739

Timm-Bottos, J. (2011). The "five and dime": Developing a community's access to art-based research. In H. Burt (Ed.), Art Therapy and Postmodernism: Creative healing through a prism (pp. $97-$ 117). Jessica Kingsley.

Timm-Bottos, J. (2016). Beyond counselling and psychotherapy, there is a field. I'll meet you there. Art Therapy: Journal of the American Art Therapy Association, 33(3), 160-162. https://doi.org/ 10.1080/07421656.2016.1199248

Timm-Bottos, J., \& Reilly, C. (2014). Learning in third spaces: Community art studio as store front university classroom. American Journal of Community Psychology; Advancing Theory, Research, and Action, 55, 102-114. https://doi.org/10.1007/s10464-014-9688-5

Timm-Bottos, J., \& Reilly, R. C. (2015). Neighbourhood art hives: Engaging communities in teaching and learning. In M. Parks \& S. Fondrie (Eds.), Service-learning and Civic Engagement: A sourcebook (pp. 179-184). Sage Publishers.

Wolff, T. (2010). The Power of Collaborative Solutions: Six principles and effective tools for building healthy communities. Jossey-Bass Publishers.

Wolff, T. (2014). Community psychology practice: Expanding the impact of psychology's work. The American Psychologist, 69(8), pp. 803-813. https://doi.org/10.1037/a0037426

Yalom, I., \& Leszcz, M. (2005). The Theory and Practice of Group Psychotherapy (5 ${ }^{\text {th }}$ ed.). Basic Books. 